\title{
A Flexible Aromatic Tetracarboxylate as a New Linker for Coordination Polymers
}

\author{
Wenjun $\mathrm{Gu}^{1}$, Jinzhong $\mathrm{Gu}^{2, *}$ and Alexander M. Kirillov ${ }^{3,4, *(1)}$ \\ 1 School of Life Sciences, Fudan University, Shanghai 200438, China; 18210700111@fudan.edu.cn \\ 2 Colleague of Chemistry and Chemical Engineering, Lanzhou University, Lanzhou 730000, China \\ 3 Centro de Química Enstrutural, Instituto Superior Técnico, Universidade de Lisboa, Av. Rovisco Pais, \\ 1049-001 Lisbon, Portugal \\ 4 Research Institute of Chemistry, Peoples's Friendship University of Russia (RUDN University), \\ 6Miklukho-Maklaya st., 117198 Moscow, Russia \\ * Correspondence: gujzh@lzu.edu.cn (J.G.); kirillov@tecnico.ulisboa.pt (A.M.K.); Tel.: +86-931-8915196 (J.G.); \\ +351-218419396 (A.M.K.)
}

Received: 17 December 2019; Accepted: 29 January 2020; Published: 3 February 2020

\begin{abstract}
Two new cadmium(II)-based materials, featuring two-dimensional (2D) $\left[\mathrm{Cd}_{2}\left(\mu_{6} \text {-deta) }(\text { bpy })\left(\mathrm{H}_{2} \mathrm{O}\right)\right]_{\mathrm{n}}(\mathbf{1})\right.$ and three-dimensional (3D) $\left[\mathrm{Cd}_{2}\left(\mu_{5} \text {-deta) }(\text { bpy })_{2}\left(\mathrm{H}_{2} \mathrm{O}\right)\right]_{\mathrm{n}}(2)\right.$ structures, were constructed by the hydrothermal method from 2,3', $4^{\prime}, 5$-diphenyl ether tetracarboxylic acid $\left(\mathrm{H}_{4}\right.$ deta) as an unexplored linker in research on coordination polymers (CPs) and 2,2'-bipyridine (bpy) as a mediator of crystallization. Microcrystalline samples of $\mathbf{1}$ and $\mathbf{2}$ were analyzed by IR/PXRD/EA/TGA and X-ray diffraction using single crystals. Structures and topologies of CPs 1 and 2 were established, revealing a 4,6L45 topological layer in 1 and a 3,5T1 topological framework in 2. Structural differences for $\mathbf{1}$ and $\mathbf{2}$ are attributed to distinct molar ratios between $\mathrm{Cd}^{2+}$ and bpy during the hydrothermal synthesis. Luminescence and thermal behavior of the obtained materials were also investigated. The present work opens up the use of an unexplored 2,3', $4^{\prime}, 5$-diphenyl ether tetracarboxylic acid as a versatile and flexible linker toward the generation of functional coordination polymer materials.
\end{abstract}

Keywords: coordination polymers (CPs); metal-organic frameworks (MOFs); carboxylic acids; hydrothermal generation; topological analysis; luminescent materials

\section{Introduction}

Coordination polymers (CPs) and metal-organic frameworks (MOFs) have been extensively explored in different chemistry branches on account of their unique and diverse structures, remarkable functional properties, and important application in a wide variety of fields, which, among others, includes gas adsorption and storage [1-4], catalysis [5-9], molecular magnetism [10-12], and photochemistry [13-16]. In the synthesis of functional CPs and derived materials, various structural and experimental parameters, such as a metal-ion coordination environment and ligand type [17-19], $\mathrm{pH}$ value [20,21], solvent composition [22,23], and temperature [24-26], can play structure-guiding roles. In particular, the variation in the types of organic building blocks has been one of the most prolific routes in building up a large library of functional CPs/MOFs [13-15,25-29]. Different aromatic multicarboxylic acids embody a well-explored and adaptable class of ligands for constructing diverse $\mathrm{CPs} / \mathrm{MOFs}$, namely due to their ample coordination behavior, varying levels of deprotonation, good thermal stability, and involvement in H-bond interactions [1,12,13,20,27].

As an extension of our broad interest in bringing new types of multicarboxylic acids to construct metal-organic architectures [30-32], we have focused on 2,3' $4^{\prime}, 5$-diphenyl ether tetracarboxylic acid 
( $\mathrm{H}_{4}$ deta) as a main and still unstudied building block, and probed its reactivity toward cadmium(II) $(\mathrm{Cd}(\mathrm{II}))$ ions in the presence of different amounts of 2,2'-bipyridine (bpy) as a mediator of crystallization. $\mathrm{H}_{4}$ deta has been selected due to several reasons: (A) this acid features some flexibility due to two phenyl rings interconnected via an O-ether group; (B) it contains two different functionalities (i.e., O-ether and $\mathrm{COOH}$ ) with nine potential coordination sites that can lead to metal-organic networks of distinct dimensionality and topology; and (C) $\mathrm{H}_{4}$ deta remains unexplored for the design of new $\mathrm{CPs} / \mathrm{MOFs}$ [33].

We describe in the present study the hydrothermally assisted preparation, structural characterization, topologies, thermal stability, and luminescence of new cadmium CPs/MOFs built from $\mathrm{H}_{4}$ deta, which feature highly complex metal-organic architectures. The obtained materials represent the unique $\mathrm{Cd}$ (II) derivatives assembled from 2,3' $4^{\prime}, 5$-diphenyl ether tetracarboxylic acid (shown in Chart 1) and open up the use of such a multicarboxylate spacer toward assembling new metal-organic architectures.<smiles>O=C(O)c1ccc(C(=O)O)c(Oc2ccc(C(=O)O)c(C(=O)O)c2)c1</smiles>

Chart 1. 2,3' $4^{\prime}, 5$-diphenyl ether tetracarboxylic acid $\left(\mathrm{H}_{4} \mathrm{deta}\right)$.

\section{Description of Experiments}

\subsection{Reagents and Equipment}

The analytical (A.R.) grade reagents were used with no further purification. $\mathrm{H}_{4}$ deta was supplied by Jinan Henghua Sci. \& Tec. Co., Ltd. A Bruker EQUINOX 55 apparatus was utilized to measure infrared spectra. An Elementar Vario EL device was used to run elemental analyses. A Rigaku-Dmax/2400 diffractometer was employed for recording PXRD data $(\lambda=1.54060 \AA, \mathrm{Cu}-\mathrm{K} \alpha)$. A LINSEIS STA/PT1600 apparatus was utilized for carrying out TGA measurements (an $\mathrm{N}_{2}$ gas atmosphere, a heating speed of $5{ }^{\circ} \mathrm{C}$ per minute, and a $20-900^{\circ} \mathrm{C}$ temperature interval). An Edinburgh FLS920 device was used for measuring excitation/emission behavior. The quantum yields of the compounds were determined by an absolute method using an integrating sphere ( $150 \mathrm{~mm}$ diameter, $\mathrm{BaSO}_{4}$ coating) from the Edinburgh FLS920 instrument.

\subsection{Synthesis of $\left[\mathrm{Cd}_{2}\left(\mu_{6} \text {-deta)(bpy) }\left(\mathrm{H}_{2} \mathrm{O}\right)\right]_{n}(\mathbf{1})\right.$}

$\mathrm{CdCl}_{2} \cdot \mathrm{H}_{2} \mathrm{O}(0.2 \mathrm{mmol}, 40 \mathrm{mg}), \mathrm{H}_{4}$ deta $(0.1 \mathrm{mmol}, 35 \mathrm{mg})$, bpy $(0.1 \mathrm{mmol}, 16 \mathrm{mg}), \mathrm{NaOH}(0.4 \mathrm{mmol}$, $16 \mathrm{mg}$ ), and $\mathrm{H}_{2} \mathrm{O}(10 \mathrm{~mL}$ ) were placed into a stainless steel vessel (Teflon-lined, $25 \mathrm{~mL}$ ) and stirred continuously for 15 minutes at $25^{\circ} \mathrm{C}$. After this stage, the vessel was closed and subjected to heating at $160{ }^{\circ} \mathrm{C}$ for three days, followed by cooling to room temperature (with a rate of $10^{\circ} \mathrm{C}$ per hour). Colorless single crystals were manually recovered, rinsed by water (distilled), and left to dry to provide product 1 in a $48 \%$ yield relative to $\mathrm{H}_{4}$ deta. Elemental analysis calculated for $\mathrm{C}_{52} \mathrm{H}_{32} \mathrm{Cd}_{4} \mathrm{~N}_{4} \mathrm{O}_{20}$ : C 42.13, H 2.18, N 3.78\%. Experimental: C 41.95, H 2.16, N 3.76\%. IR (main bands, $\mathrm{cm}^{-1}, \mathrm{KBr}$ ): $3076 \mathrm{w}$, $1627 \mathrm{w}, 1588 \mathrm{~s}, 1560 \mathrm{~s}, 1537 \mathrm{~s}, 1487 \mathrm{w}, 1470 \mathrm{w}, 1442 \mathrm{w}, 1399 \mathrm{~s}, 1354 \mathrm{~m}, 1265 \mathrm{w}, 1230 \mathrm{~m}, 1158 \mathrm{w}, 1086 \mathrm{w}$, 1013 w, 1021 w, 968 w, 929 w, 890 w, 847 w, 829 w, 813 w, 767 m, 735 w, 651 w, 629 w, 590 w.

\subsection{Synthesis of $\left[C d_{2}\left(\mu_{5}-\text { deta }\right)(\text { bpy })_{2}\left(\mathrm{H}_{2} \mathrm{O}\right)\right]_{n}(2)$}

CP 2 was synthesized as colorless single crystals following the procedure for 1, but using a different amount of bpy $(0.2 \mathrm{mmol}, 31 \mathrm{mg})$. Yield was $38 \%$ relative to $\mathrm{H}_{4}$ deta. Elemental analysis calculated for $\mathrm{C}_{36} \mathrm{H}_{24} \mathrm{Cd}_{2} \mathrm{~N}_{4} \mathrm{O}_{10}$ : C 48.18, H 2.70, N 6.24\%. Experimental: C 48.37, H 2.71, N 6.21\%. IR 
(main bands, cm ${ }^{-1}$, KBr): 3439 w, 3061 w, 1582 s, 1537 s, 1476 w, 1431 m, 1392 s, 1315 w, 1264 w, 1230 m, 1170 w, 1153 w, 1086 w, 1058 w, 1013 w, 974 w, 929 w, 901 w, 879 w, 851 w, 829 w, 776 m, 727 w, 710 w, $644 \mathrm{w}, 616 \mathrm{w}, 550 \mathrm{w}$.

\subsection{Structural Determination (Single-crystals)}

X-ray data for 1 and 2 were collected on a Bruker APEX-II/CCD diffractometer $(\lambda=0.71073 \AA$, Mo $K_{\alpha}$ ). SADABS software was used for correcting absorption (the semi-empirical method). The crystal structure of each sample was determined using a direct method, followed by refinement (full-matrix/least-squares on $F^{2}$ ) aided by the SHELXS-97/SHELXL-97 software [34,35]. Every non-hydrogen atom underwent an anisotropic refinement (full-matrix/least-squares on $F^{2}$ ). Every hydrogen atom (excluding $\mathrm{H}_{2} \mathrm{O}$ ) was added to a calculated position (fixed isotropic/thermal parameters) and taken into account at the ultimate stage when calculating structure factors. $\mathrm{H}$ atoms in water molecules were found using difference maps and fixed to the corresponding oxygen centers. Crystallographic parameters are given in Table 1, while the bonding data are provided in supplementary Tables S1 and S2. Analysis of topologies in 1 and 2 was carried out using an underlying network concept [36,37]. Simplified networks were created upon the elimination of bpy and $\mathrm{H}_{2} \mathrm{O}$ moieties, along with performing a reduction of the deta ${ }^{4-}$ ligands to their centroids. CCDC-1,961,692 (1) and $1,961,693$ (2) encompass all the structural parameters.

Table 1. Crystal data for coordination polymers (CPs) 1 and 2.

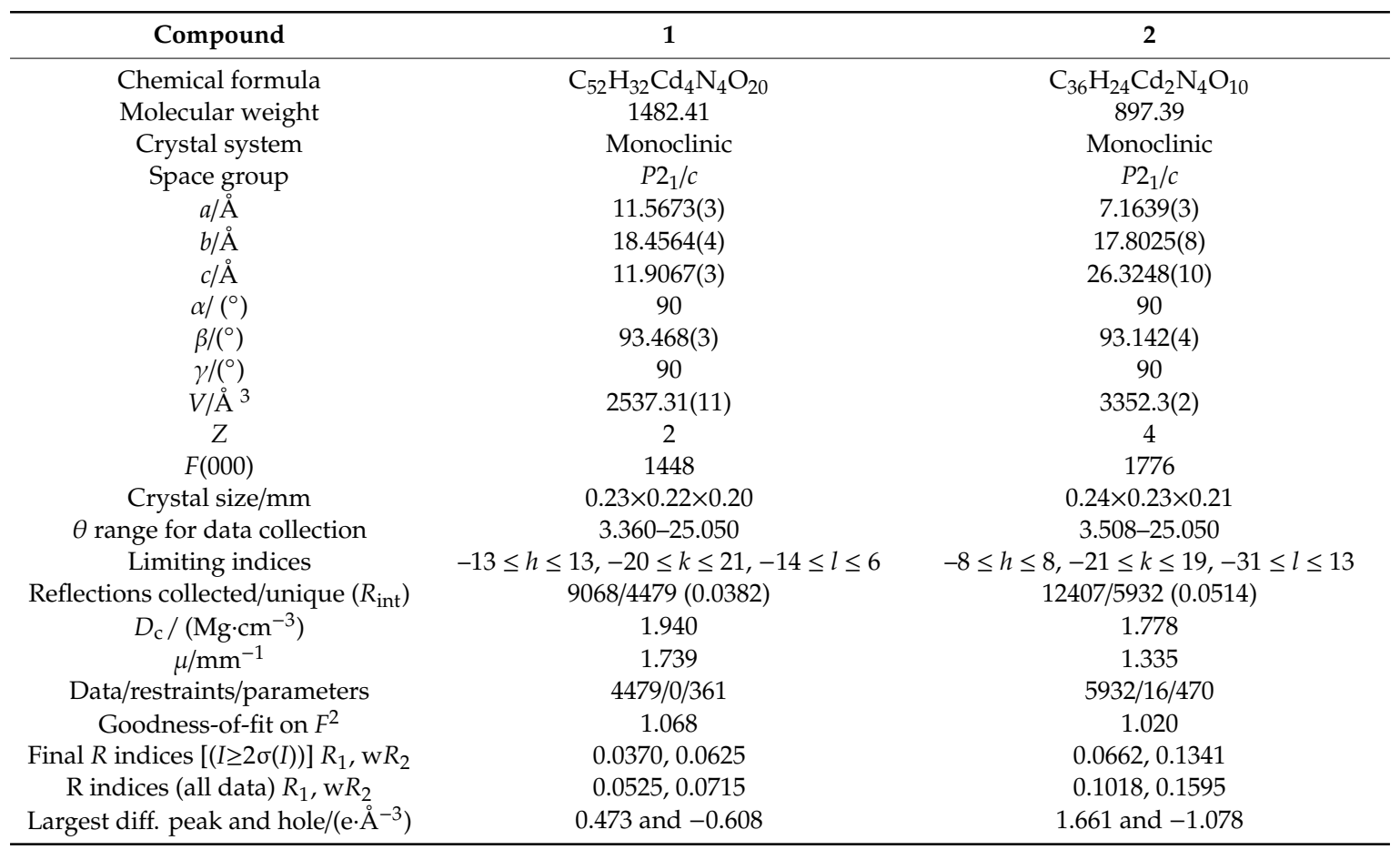

\section{Discussion of Results}

\subsection{Preparation of $\mathbf{1}$ and $\mathbf{2}$}

Owing to the unique conditions of pressure and temperature, the hydrothermal synthetic method is specifically attractive to form CPs/MOFs [38-41]. Hence, herein, we attempted the application of hydrothermal synthesis for the generation of coordination polymers using 2,3',4',5-diphenyl ether tetracarboxylic acid as an unexplored linker. Reactions involving the $\mathrm{H}_{2} \mathrm{O}$ solutions of $\mathrm{CdCl}_{2} \cdot \mathrm{H}_{2} \mathrm{O}, \mathrm{H}_{4}$ deta (the linker source), $\mathrm{NaOH}$ (a base to deprotonate the tetracarboxylic acid ligand), and 2,2'-bipyridine (the mediator of crystallization) resulted in two new products formulated as 
$\left[\mathrm{Cd}_{2}\left(\mu_{6} \text {-deta)(bpy) }\left(\mathrm{H}_{2} \mathrm{O}\right)\right]_{\mathrm{n}}(\mathrm{CP} \mathbf{1})\right.$ and $\left[\mathrm{Cd}_{2}\left(\mu_{5} \text {-deta }\right)(\text { bpy })_{2}\left(\mathrm{H}_{2} \mathrm{O}\right)\right]_{\mathrm{n}}(\mathrm{CP} 2)$. It should be mentioned that both compounds were synthesized using a similar procedure but different molar ratios between bpy and $\mathrm{Cd}^{2+}$, namely $1: 2$ in $\mathbf{1}$ and 1:1 in $\mathbf{2}$. No crystals were obtained in the absence of 2,2'-bipyridine (the crystallization mediator). Reactions using other molar ratios between bpy and $\mathrm{Cd}^{2+}$ (e.g., 2:1; 1:3) were also attempted but failed to produce suitable crystals or gave a mixture of products in low yields. Both products were obtained as analytically pure and stable microcrystals (including single crystals) and analyzed using conventional methods (IR/EA/PXRD/TGA) along with X-ray structural analysis (single crystals), which permitted us to establish their intricate two-dimensional (2D) and three-dimensional (3D) structures.

\subsection{Structural Features of $\left[\mathrm{Cd}_{2}\left(\mu_{6}-\text { deta }\right)(\text { bpy })\left(\mathrm{H}_{2} \mathrm{O}\right)\right]_{n}(\mathrm{CP} \mathbf{1})$}

This compound reveals a 2D coordination network (Figure 1). The asymmetric entity is composed of two cadmium(II) atoms ( $\mathrm{Cd} 1$ and $\mathrm{Cd} 2$ ), one $\mu_{6}$-deta ${ }^{4-}$ linker, one terminal bpy, and one $\mathrm{H}_{2} \mathrm{O}$ ligand. The seven-coordinate $\mathrm{Cd} 1$ center adopts a deformed pentagonal bipyramid $\left(\mathrm{CdO}_{7}\right)$ environment that is occupied by carboxylate oxygen donors coming from four $\mu_{6}$-deta $^{4-}$ moieties. The six-coordinate $\mathrm{Cd} 2$ atom features a deformed octahedral $\left(\mathrm{CdN}_{2} \mathrm{O}_{4}\right)$ geometry, occupied by three oxygen atoms of two $\mu_{6}$-deta ${ }^{4-}$ blocks, one $\mathrm{H}_{2} \mathrm{O}$ ligand, and a pair of bpy nitrogen atoms (Figure 1a). The cadmium-oxygen (2.224(3)-2.483(10) $\AA$ ) and cadmium-nitrogen (2.293(4)-2.321(4) $\AA$ ) distances are usual for related types of compounds $[12,13,20]$. The deta ${ }^{4-}$ ligand functions as a $\mu_{6}$-spacer (Scheme 1 , mode-I), wherein the four carboxylate functionalities are bidentate, tridentate, or bidentate with a bridging mode. Also, $\mu_{6}$-deta ${ }^{4-}$ is bent with an $84.67^{\circ}$ angle (a dihedral one between two aromatic functionalities), while another relevant Carbon- $\mathrm{O}_{\text {ether }}-\mathrm{Carbon}$ angle is $117.21^{\circ}$. Four contiguous cadmium nodes are interlinked by six carboxylate functionalities (these come from four $\mu_{6}$-deta ${ }^{4-}$ linkers), generating a tetracadmium(II) subunit (Figure $1 \mathrm{~b}$ ). These $\mathrm{Cd}_{4}$ subunits are additionally connected by the remaining carboxylate functionalities of $\mu_{6}$-deta ${ }^{4-}$, forming a two-dimensional net structure (Figure $1 c$ ). The structure of $\mathbf{1}$ has no porosity and solvent-accessible voids.

A topological examination of this 2D CP disclosed a two-nodal four, six-interconnected net (Figure 1d), which is assembled from four-linked Cd1 nodes, six-linked $\mu_{6}$-deta ${ }^{4-}$ nodes, and two-interconnected Cd2 linkers. This layer belongs to a 4,6L45 topological type and is characterized by a point symbol of $\left(3.4^{4} \cdot 6\right)\left(3^{2} \cdot 4^{4} \cdot 5^{5} \cdot 6^{3} .7\right)$; here, the $\left(3.4^{4} \cdot 6\right)$ and $\left(3^{2} \cdot 4^{4} \cdot 5^{5} \cdot 6^{3} .7\right)$ notations relate to $\mathrm{Cd} 1$ and $\mu_{6}$-deta $^{4-}$ nodes, respectively.

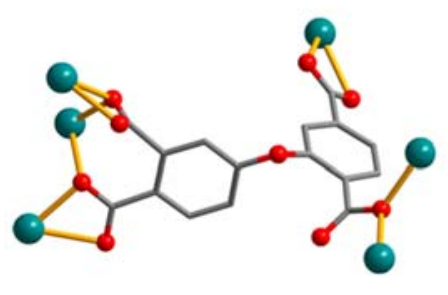

I

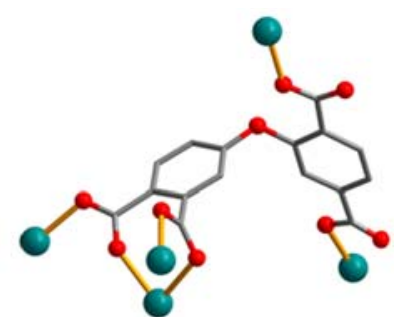

II

Scheme 1. Distinct modes of coordination for $\mu_{6}$-deta $^{4-}$ in $\mathbf{1}$ (mode-I) and $\mu_{5}$-deta $^{4-}$ in $\mathbf{2}$ (mode-II). 


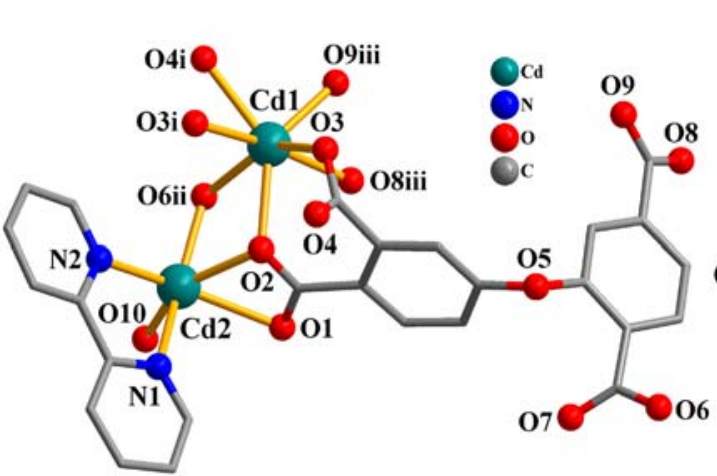

(a)

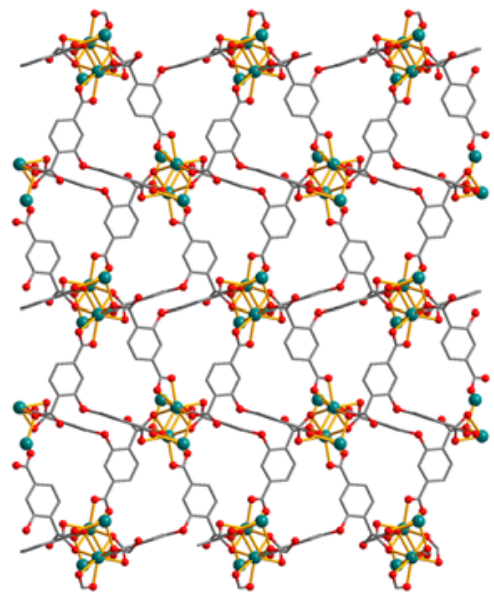

(c)

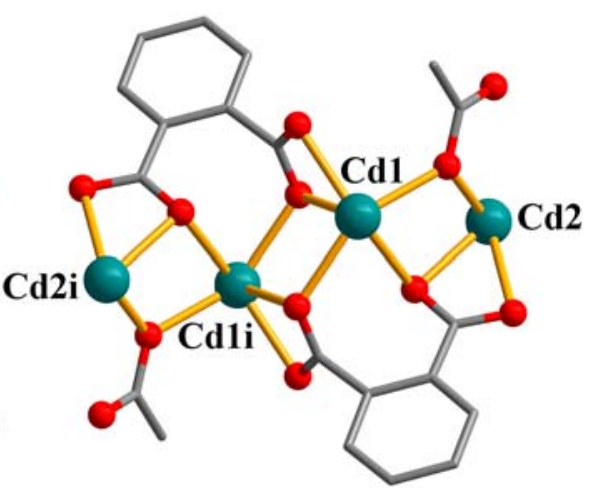

(b)

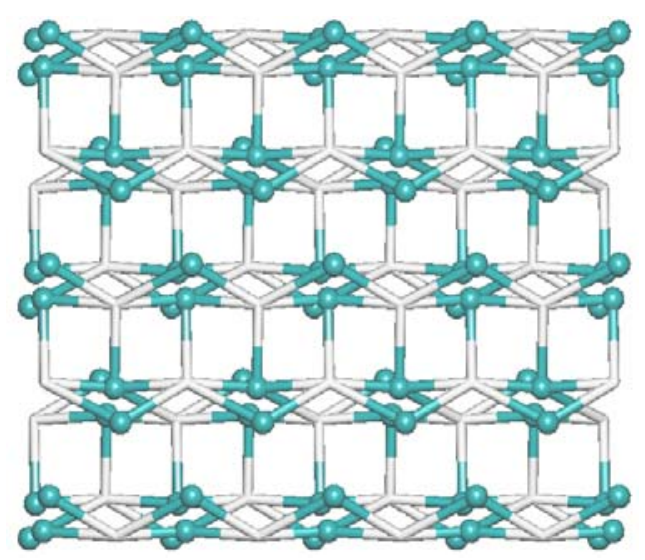

(d)

Figure 1. Representations of the structure of 1. (a) Coordination environment and connectivity of cadmium (Cd) atoms. (b) A tetracadmium(II) subunit. (c) A two-dimensional (2D) coordination polymer structure (view along the $a$ axis). (d) Topological view of a simplified 2D net representing a two-nodal 4,6-c layer of the 4,6L45 topological type. View along the $a$ axis; 2-c Cd2 linkers and 4-c Cd1 nodes (balls, turquoise), centroids of 6-c $\mu_{6}$-deta ${ }^{4-}$ nodes (gray sticks).

\subsection{Structural Features of $\left[\mathrm{Cd}_{2}\left(\mu_{5} \text {-deta }\right)(\text { bpy })_{2}\left(\mathrm{H}_{2} \mathrm{O}\right)\right]_{n}(2)$}

If compared to 1, compound 2 (Figure 2) discloses a more complex 3D coordination polymer structure. This asymmetric entity bears a couple of cadmium atoms $(\mathrm{Cd} 1 / \mathrm{Cd} 2)$, one $\mu_{5}$-deta ${ }^{4-}$ block, two bpy moieties, and one terminal $\mathrm{H}_{2} \mathrm{O}$ ligand. As represented in Figure 2a, the six-coordinate $\mathrm{Cd} 1$ atom has a deformed octahedral $\left(\mathrm{CdN}_{2} \mathrm{O}_{4}\right)$ geometry, taken by a pair of $\mathrm{N}$ donors from bpy and four carboxylate oxygen donors from three $\mu_{5}$-deta $^{4-}$ linkers. The five-coordinate $\mathrm{Cd} 2$ center features a deformed trigonal bipyramid $\left(\mathrm{CdN}_{2} \mathrm{O}_{3}\right)$ geometry, composed of a couple of oxygen atoms from two $\mu_{5}$-deta ${ }^{4-}$ linkers, a water ligand, and a couple of $\mathrm{N}$ atoms from bpy. The cadmium-oxygen distances span in the 2.228(10)-2.450(6) A range, whereas the cadmium-nitrogen bonds vary between 2.288(9) and $2.388(7) \AA$; these lie within standard values [31,42]. In 2 , the deta ${ }^{4-}$ block takes a $\mu_{5}$-coordination mode (mode-II, Scheme 1) wherein the carboxylate functionalities are mono- or $\mu$-bidentate. In $\mu_{5}$-deta ${ }^{4-}$, important angles are $88.92^{\circ}$ (the dihedral angle between phenyl rings) and $117.67^{\circ}$ (the $\mathrm{C}-\mathrm{O}_{\text {ether }}-\mathrm{C}$ angle). The $\mu_{5}$-deta ${ }^{4-}$ linkers interconnect the $\mathrm{Cd}(\mathrm{II})$ centers to a three-dimensional metal-organic net (Figure $2 b$ ). Upon removal of a coordinated water molecule, the PLATON analysis of 2 reveals a minor porosity with an effective free volume of $2.1 \%$ of the crystal volume [43]. 


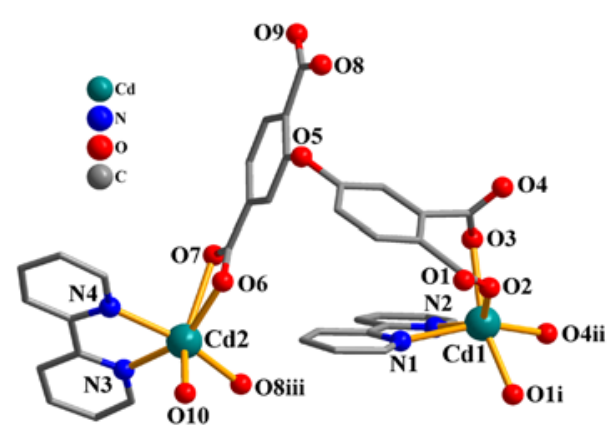

(a)

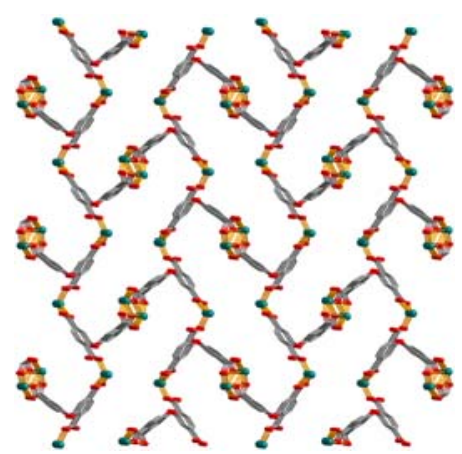

(b)

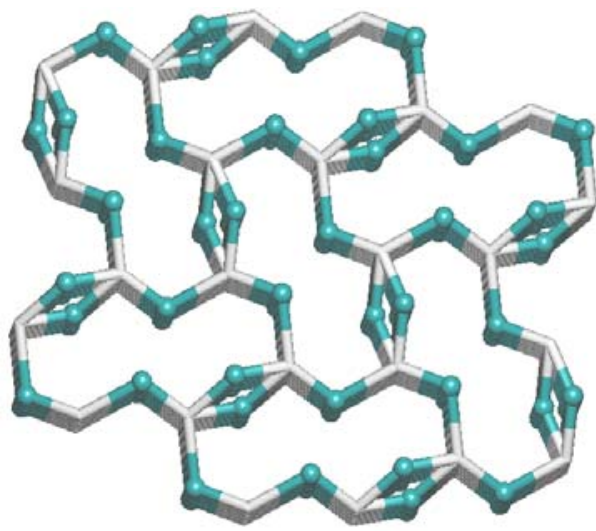

(c)

Figure 2. Representations of the structure of 2. (a) Coordination environment and connectivity of Cd atoms. (b) Three-dimensional (3D) coordination polymer structure (view along the $a$ axis). (c) Topological view of a simplified 3D network representing a two-nodal 3,5-c net of the 3,5T1 topological type. View along the $a$ axis; 2-c Cd2 linkers and 3-c Cd1 nodes (balls, turquoise), centroids of 5-c $\mu_{5}$-deta $^{4-}$ nodes (gray sticks).

Regarding the topological classification, this 3D CP is composed of three-linked Cd1 nodes, five-linked $\mu_{5}$ - deta ${ }^{4-}$ nodes, and two-interconnected $\mathrm{Cd} 2$ linkers (Figure $2 \mathrm{c}$ ). The resulting underlying framework is a two-nodal three,five-interconnected net of 3,5T1 topological type. This is described by a $\left(4^{2} \cdot 6^{5} .8^{3}\right)\left(4^{2} .6\right)$ point symbol where the $\left(4^{2} \cdot 6^{5} \cdot 8^{3}\right)$ and $\left(4^{2} .6\right)$ indices relate to $\mu_{5}$-deta ${ }^{4-}$ and $\mathrm{Cd} 1$ nodes, respectively.

\subsection{Discussion of TGA and PXRD, Porosity, and Gas Sorption}

The stability of CPs 1 and 2 was investigated by TGA (Figure 3) upon heating from $25^{\circ} \mathrm{C}$ to $800{ }^{\circ} \mathrm{C}$ using an inert gas flow $\left(\mathrm{N}_{2}\right)$. As expected, compound 1 discloses the loss of an $\mathrm{H}_{2} \mathrm{O}$ ligand in the 157-199 ${ }^{\circ} \mathrm{C}$ temperature range (experimental, $2.3 \%$; calculated, $2.4 \%$ ); after dehydration, the remaining sample is thermally stable on heating till $334^{\circ} \mathrm{C}$. Similarly, compound 2 exhibits a mass decrease in the $162-195{ }^{\circ} \mathrm{C}$ range, which is associated with the release of one $\mathrm{H}_{2} \mathrm{O}$ ligand (experimental, $2.2 \%$; calculated $2.0 \%$ ), while the dehydrated sample maintains its integrity till $346^{\circ} \mathrm{C}$. $\mathrm{CdO}$ is expected as a final decomposition product of both coordination polymers. The decomposition is complete at $819^{\circ} \mathrm{C}$ or $881{ }^{\circ} \mathrm{C}$ for $\mathbf{1}$ and 2, respectively. The experimentally observed remaining weights of $34.5 \%(\mathbf{1})$ and $28.8 \%$ (2) are in very good agreement with the values calculated for $\mathrm{CdO}$, i.e., $34.6 \%$ (1) and $28.6 \%$ (2). 


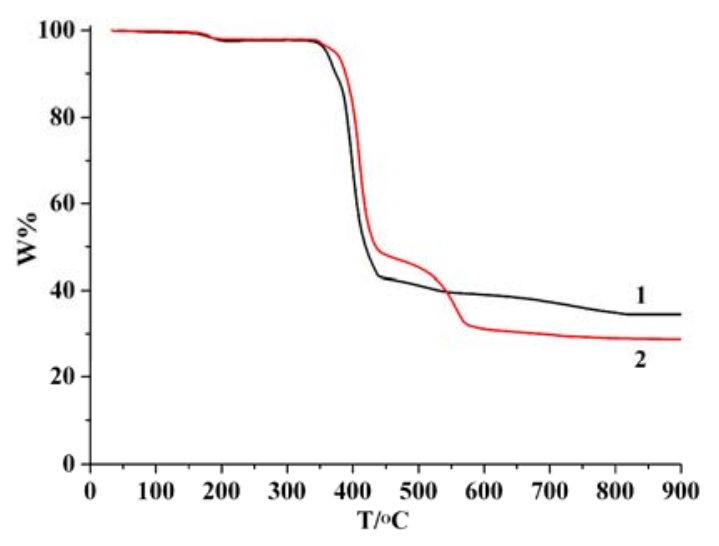

Figure 3. TGA curves for compounds 1 and 2.

A bulk, crystalline sample of each coordination polymer (1 and 2) was studied using a PXRD method. Experimental (as-synthesized) and simulated PXRD patterns are given in (Supplementary Materials) Figures S1 and S2. Their comparison indicates a good match and confirms the phase purity of the synthesized products.

Given the presence of some porosity in $\mathbf{2}$ (2.1\% of the effective void volume after activating and removing the water ligand), gas sorption measurements were also performed (for details, see Table S3). These were carried out on the activated samples by recording the $\mathrm{N}_{2}$ adsorption/desorption isotherms at $77 \mathrm{~K}$, resulting in the adsorbed $\mathrm{N}_{2}$ amount of $1.0 \mathrm{~cm}^{3} / \mathrm{g}$ at $77 \mathrm{~K}$ and $1 \mathrm{~atm}$. The BET surface area of $0.58 \mathrm{~m}^{2} / \mathrm{g}$ was also established.

\section{Concluding Remarks}

We have explored the simple, aqueous medium protocol (hydrothermal synthesis) to obtain two new two- or three-dimensional CPs/MOFs derived from 2,3' $4^{\prime}, 5$-diphenyl ether tetracarboxylic acid $\left(\mathrm{H}_{4}\right.$ deta) as an unexplored linker in research on metal-organic frameworks and coordination polymers. In fact, CPs 1 and 2 represent unique examples of metal-containing derivatives constructed from $\mathrm{H}_{4}$ deta. This work thus extends a variety of multifunctional carboxylic acids applied in the synthesis of coordination polymers [44-50].

The structures of metal-organic nets and the corresponding topologies in the synthesized compounds have also been underscored, revealing underlying networks of the 4,6L45 and 3,5T1 topological types, respectively. This study has also shown that the use of 2,2 -bipyridine as a crystallization mediator in a different stoichiometry to $\mathrm{Cd}^{2+}$ nodes permits the generation of products with distinct dimensionality, structural characteristics, and topologies. Both compounds also show promising luminescent properties toward potential applications as photoactive materials.

Future studies on extending the family of $\mathrm{CPs}$ and MOFs assembled from $\mathrm{H}_{4}$ deta to other types of metals, as well as on exploring the functional properties of the obtained materials, are in progress.

Supplementary Materials: The following are available online at http://www.mdpi.com/2073-4352/10/2/84/s1, Figures S1 and S2: PXRD patterns, Figure S3: emission spectra and discussion of luminescent properties, Tables S1 and S2: selected structural parameters for $\mathbf{1}$ and 2, Table S3: gas sorption data for $\mathbf{2}$.

Author Contributions: Conceptualization, J.G. and A.M.K.; data curation, W.G.; funding acquisition, J.G. and A.M.K.; investigation, W.G., J.G., and A.M.K.; methodology, J.G.; visualization, J.G. and A.M.K.; writing-original draft, W.G., J.G., and A.M.K.; writing-review and editing, A.M.K. All authors have read and agreed to the published version of the manuscript.

Acknowledgments: This work was supported by the Foundation for Science and Technology (FCT) and Portugal 2020 (LISBOA-01-0145-FEDER-029697, UIDB/00100/2020). The publication was also prepared with the support of the RUDN University Program 5-100.

Conflicts of Interest: The authors declare no conflicts of interest. 


\section{References}

1. Glover, T.G.; Mu, B. Gas Adsorption in Metal-Organic Frameworks: Fundamentals and Applications; CRC Press: Boca Raton, FL, USA, 2018.

2. Hashemi, L.; Morsali, A. Pillared Metal-Organic Frameworks: Properties and Applications; John Wiley \& Sons: Hoboken, NJ, USA, 2019.

3. Fu, H.R.; Zhao, Y.; Zhou, Z.; Yang, X.G.; Ma, L.F. Neutral ligand TIPA-based two 2D metal-organic frameworks: Ultrahigh selectivity of $\mathrm{C}_{2} \mathrm{H}_{2} / \mathrm{CH}_{4}$ and efficient sensing and sorption of $\mathrm{Cr}(\mathrm{VI})$. Dalton Trans. 2018, 47, 3725-3732. [CrossRef] [PubMed]

4. Zhu, J.; Usov, P.M.; Xu, W.Q.; Celis-Salazar, P.J.; Lin, S.Y.; Kessinger, M.C.; Landaverde-Alvarado, C.; Cai, M.; May, A.M.; Slebodnick, C.; et al. A new class of metal-cyclam-based zirconium metal-organic frameworks for $\mathrm{CO}_{2}$ adsorption and chemical fixation. J. Am. Chem. Soc. 2018, 140, 993-1003. [CrossRef] [PubMed]

5. Gu, J.Z.; Wen, M.; Cai, Y.; Shi, Z.F.; Arol, A.S.; Kirillova, M.V.; Kirillov, A.M. Metal-organic architectures assembled from multifunctional polycarboxylates: hydrothermal self-assembly, structures, and catalytic activity in alkane oxidation. Inorg. Chem. 2019, 58, 2403-2412. [CrossRef] [PubMed]

6. Sotnik, S.A.; Polunin, R.A.; Kiskin, M.A.; Kirillov, A.M.; Dorofeeva, V.N.; Gavrilenko, K.S.; Eremenko, I.L.; Novotortsev, V.M.; Kolotilov, S.V. Heterometallic Coordination Polymers Assembled from Trigonal Trinuclear $\mathrm{Fe}_{2} \mathrm{Ni}$-Pivalate Blocks and Polypyridine Spacers: Topological Diversity, Sorption, and Catalytic Properties. Inorg. Chem. 2015, 54, 5169-5181. [CrossRef]

7. Chen, Y.Z.; Zhang, R.; Jiao, L.; Jiang, H.L. Metal-organic framework-derived porous materials for catalysis. Coord. Chem. Rev. 2018, 362, 1-23. [CrossRef]

8. Hu, M.L.; Safarifard, V.; Doustkhah, E.; Rostamnia, S.; Morsali, A.; Nouruzi, N.; Beheshti, S.; Akhbari, K. Taking organic reactions over metal-organic frameworks as heterogeneous catalysis. Micropor. Mesopor. Mat. 2018, 256, 111-127. [CrossRef]

9. Kirillov, A.M.; Coelho, J.A.S.; Kirillova, M.V.; Guedes da Silva, M.F.C.; Nesterov, D.S.; Gruenwald, K.R.; Haukka, M.; Pombeiro, A.J.L. Bringing an "old" biological buffer to coordination chemistry: New 1D and 3D coordination polymers with $\left[\mathrm{Cu}_{4}(\mathrm{Hbes})_{4}\right]$ cores for mild hydrocarboxylation of alkanes. Inorg. Chem. 2010, 49, 6390-6392. [CrossRef]

10. Espallargas, G.M.; Coronado, E. Magnetic functionalities in MOFs: From the framework to the pore. Chem. Soc. Rev. 2018, 47, 533-557. [CrossRef]

11. Karabach, Y.Y.; Kirillov, A.M.; Haukka, M.; Sanchiz, J.; Kopylovich, M.N.; Pombeiro, A.J.L. Multicopper(II) pyromellitate compounds: Self-assembly synthesis, structural topologies and magnetic features. Cryst. Growth Des. 2008, 8, 4100-4108. [CrossRef]

12. Xu, G.C.; Zhang, W.; Ma, X.M.; Chen, Y.H.; Zhang, L.; Cai, H.L.; Wang, Z.M.; Xiong, R.G.; Gao, S. Coexistence of magnetic and electric orderings in the metal-formate frameworks of $\left[\mathrm{NH}_{4}\right]\left[\mathrm{M}(\mathrm{HCOO})_{3}\right]$. J. Mater. Chem. A 2011, 133, 14948-14951. [CrossRef]

13. Cui, Y.L.; Yue, Y.F.; Qian, G.D.; Chen, B.L. Luminescent functional metal-organic frameworks. Chem. Rev. 2012, 112, 1126-1162. [CrossRef] [PubMed]

14. Gao, L.L.; Zhang, J.; Zhai, L.J.; Niu, X.Y.; Hu, T.P. Gas adsorption and fluorescent sensing properties of three metal-organic frameworks based on 3,5-di( $2^{\prime}, 5^{\prime}$-dicarboxylphenyl)benozoic acid and cadmium ions. J. Solid State Chem. 2019, 271, 346-353. [CrossRef]

15. Huang, R.W.; Wei, Y.S.; Dong, X.Y.; Wu, X.H.; Du, C.X.; Zang, S.Q.; Mak, T.C. Hypersensitive dual-function luminescence switching of a silver-chalcogenolate cluster-based metal-organic framework. Nat. Chem. 2017, 9, 689-697. [CrossRef] [PubMed]

16. Chen, W.M.; Meng, X.L.; Zhuang, G.L.; Wang, Z.; Kurmoo, M.; Zhao, Q.Q.; Wang, X.P.; Shan, B.R.; Tung, C.H.; Sun, D. A superior fluorescent sensor for $\mathrm{Al}^{3+}$ and $\mathrm{UO}_{2}{ }^{2+}$ based on a $\mathrm{Co}(\mathrm{II})$ metal-organic framework with exposed pyrimidyl Lewis base sites. J. Mater. Chem. A 2017, 5, 13079-13085. [CrossRef]

17. Gu, J.Z.; Cui, Y.H.; Liang, X.X.; Wu, J.; Lv, D.Y.; Kirillov, A.M. Structurally distinct metal-organicand H-bonded networks derived from 5-(6-carboxypyridin-3-yl)isophthalic acid: coordination and template effect of 4,4'-bipyridine. Cryst. Growth Des. 2016, 16, 4658-4670. [CrossRef]

18. Zhai, Z.W.; Yang, S.H.; Luo, P.; Li, L.K.; Du, C.X.; Zang, S.Q. Zn(II)/Cd(II) metal-organic frameworks based on the 2,5-bis(4-pyridyl)thiazolo[5,4-d]thiazole ligand. Eur. J. Inorg. Chem. 2019, 2725-2734. [CrossRef] 
19. Baladi, E.; Nobakht, V.; Tarassoli, A.; Proserpio, D.M.; Carlucci, L. Three cationic, nonporous Cu-I-coordination polymers: structural investigation and vapor iodine capture. Cryst. Growth Des. 2018, 18, 7207-7218. [CrossRef]

20. Gu, J.Z.; Gao, Z.Q.; Tang, Y. $\mathrm{pH}$ and auxiliary ligand influence on the structural variations of 5(2'-carboxylphenyl) nicotate coordination polymers. Cryst. Growth Des. 2012, 12, 3312-3323. [CrossRef]

21. An, R.; Zhao, H.; Hu, H.M.; Wang, X.F.; Yang, M.L.; Xue, G.L. Synthesis, structure, white-light emission, and temperature recognition properties of $\mathrm{Eu} / \mathrm{Tb}$ mixed coordination polymers. Inorg. Chem. 2016, 55, 871-876. [CrossRef]

22. Sánchez-Férez, F.; Bayés, L.; Font-Bardia, M.; Pons, J. Solvent dependent formation of Cu(II) complexes based on isonicotinamide ligand. Inorg. Chim. Acta 2019, 494, 112-122. [CrossRef]

23. Jaremko, Ł.; Kirillov, A.M.; Smoleński, P.; Pombeiro, A.J.L. Engineering coordination and supramolecular copper-organic networks by aqueous medium self-assembly with 1,3,5-triaza-7-phosphaadamantane (PTA). Cryst. Growth Des. 2009, 9, 3006-3010. [CrossRef]

24. Dong, Y.B.; Jiang, Y.Y.; Li, J.; Ma, J.P.; Liu, F.L.; Tang, B.; Huang, R.Q.; Batten, S.R. Temperature-dependent synthesis of metal-organic frameworks based on a flexible tetradentate ligand with bidirectional coordination donors. J. Am. Chem. Soc. 2007, 129, 4520-4521. [CrossRef] [PubMed]

25. Paz, F.A.A.; Klinowski, J.; Vilela, S.M.F.; Tomé, J.P.C.; Cavaleiro, J.A.S.; Rocha, J. Ligand design for functional metal-organic frameworks. Chem. Soc. Rev. 2012, 41, 1088-1110.

26. Wan, J.; Cai, S.L.; Zhang, K.; Li, C.J.; Feng, Y.; Fan, J.; Zheng, S.R.; Zhang, W.G. Anion- and temperature-dependent assembly, crystal structures and luminescence properties of six new $\mathrm{Cd}(\mathrm{II})$ coordination polymers based on 2,3,5,6-tetrakis(2-pyridyl)pyrazine. CrystEngComm 2016, 18, 5164-5176. [CrossRef]

27. Fernandes, T.A.; Santos, C.I.M.; André, V.; Kłak, J.; Kirillova, M.V.; Kirillov, A.M. Copper(II) Coordination Polymers Self-assembled from Aminoalcohols and Pyromellitic Acid: Highly Active Pre-catalysts for the Mild Water-promoted Oxidation of Alkanes. Inorg. Chem. 2016, 55, 125-135. [CrossRef] [PubMed]

28. Li, L.; Li, C.X.; Ren, Y.L.; Song, M.; Ma, Y.; Huang, R.D. Novel luminescent metal-organic frameworks based on rigid carboxylate ligands for highly selective sensing of $\mathrm{Fe}^{3+}$ ions. CrystEngComm 2016, 18, 7787-7795. [CrossRef]

29. Zhao, D.; Timmons, D.J.; Yuan, D.; Zhou, H.-C. Tuning the Topology and Functionality of Metal-Organic Frameworks by Ligand Design. Acc. Chem. Res. 2011, 44, 123-133. [CrossRef] [PubMed]

30. Zhao, S.Q.; Gu, J.Z. Synthesis, crystal structures and magnetic properties of Mn(II) and Ni(II) dinuclear coordination compounds constructed from biphenyl-2,4,4'-tricarboxylate and phenanthroline. Chin. J. Inorg. Chem. 2016, 32, 1611-1618.

31. Zhao, N.; Li, Y.; Gu, J.Z.; Kirillova, M.V.; Kirillov, A.M. Hydrothermal generation, structural versatility and properties of metal(II)-organic architectures driven by a pyridine-tricarboxylic acid. Dalton. Trans. 2019, 48, 8361-8374. [CrossRef]

32. Zhao, N.; Li, Y.; Gu, J.Z.; Fernandes, T.A.; Kirillova, M.V.; Kirillov, A.M. New copper(II) coordination compounds assembled from multifunctional pyridine-carboxylate blocks: Synthesis, structures, and catalytic activity in cycloalkane oxidation. Molecules 2019, 24, 6. [CrossRef]

33. Groom, C.R.; Bruno, I.J.; Lightfoot, M.P.; Ward, S.C. The Cambridge Structural Database. Acta Cryst. 2016, B72, 171-179. [CrossRef] [PubMed]

34. Sheldrick, G.M. SHELXS-97; Program for X-ray Crystal Structure Determination; University of Gottingen: Göttingen, Germany, 1997.

35. Sheldrick, G.M. SHELXL-97; Program for X-ray Crystal Structure Refinement; University of Gottingen: Göttingen, Germany, 1997.

36. Blatov, V.A. Multipurpose crystallochemical analysis with the program package TOPOS. IUCr CompComm Newsletter 2006, 7, 4-38.

37. Blatov, V.A.; Shevchenko, A.P.; Proserpio, D.M. Applied topological analysis of crystal structures with the program package topospro. Cryst. Growth Des. 2014, 14, 3576-3586. [CrossRef]

38. Gu, J.Z.; Wen, M.; Liang, X.X.; Shi, Z.F.; Kirillova, M.V.; Kirillov, A.M. Multifunctional aromatic carboxylic acids as versatile building blocks for hydrothermal design of coordination polymers. Crystals 2018, 8, 83. [CrossRef] 
39. Gu, J.Z.; Liang, X.X.; Cui, Y.H.; Wu, J.; Shi, Z.F.; Kirillov, A.M. Introducing 2-(2-carboxyphenoxy)terephthalic acid as a new versatile building block for design of diverse coordination polymers: synthesis, structural features, luminescence sensing, and magnetism. CrystEngComm 2017, 19, 2570-2588. [CrossRef]

40. Gu, J.Z.; Liang, X.X.; Cai, Y.; Wu, J.; Shi, Z.F.; Kirillov, A.M. Hydrothermal assembly, structures, topologies, luminescence, and magnetism of a novel series of coordination polymers driven by a trifunctional nicotinic acid building block. Dalton Trans. 2017, 46, 10908-10925. [CrossRef]

41. Gu, J.Z.; Cui, Y.H.; Wu, J.; Kirillov, A.M. A series of mixed-ligand 2D and 3D coordination polymers assembled from a novel multifunctional pyridine-tricarboxylate building block: Hydrothermal syntheses, structural and topological diversity, and magnetic and luminescent properties. RSC Adv. 2015, 5, 78889-78901. [CrossRef]

42. Gu, J.Z.; Cai, Y.; Wen, M.; Shi, Z.F.; Kirillov, A.M. A new series of Cd(II) metal-organic architectures driven by soft ether-bridged tricarboxylate spacers: synthesis, structural and topological versatility, and photocatalytic properties. Dalton Trans. 2018, 47, 14327-14339. [CrossRef]

43. Van de Sluis, P.; Spek, A.L. Bypass-an effective merhve method for the refinement of crystal-structures containing disordered solvent regions. Acta Crystallogr. Sect. A 1990, 46, 194-201. [CrossRef]

44. Gu, J.Z.; Cai, Y.; Qian, Z.Y.; Wen, M.; Shi, Z.F.; Lv, D.Y.; Kirillov, A.M. A new series of Co, Ni, Zn, and $\mathrm{Cd}$ metal-organic architectures driven by an unsymmetrical biphenyl-tricarboxylic acid: Hydrothermal assembly, structural features and properties. Dalton Trans. 2018, 47, 7431-7444. [CrossRef]

45. Kirillov, A.M.; Karabach, Y.Y.; Kirillova, M.V.; Haukka, M.; Pombeiro, A.J.L. Topologically unique 2D heterometallic $\mathrm{Cu}^{\mathrm{II}} / \mathrm{Mg}$ coordination polymer: synthesis, structural features, and catalytic use in alkane hydrocarboxylation. Cryst. Growth Des. 2012, 12, 1069-1074. [CrossRef]

46. Jaros, S.W.; Guedes da Silva, M.F.C.; Florek, M.; Oliveira, M.C.; Smoleński, P.; Pombeiro, A.J.L.; Kirillov, A.M. Aliphatic dicarboxylate directed assembly of silver(I) 1,3,5-triaza-7-phosphaadamantane coordination networks: topological versatility and antimicrobial activity. Cryst. Growth Des. 2014, 14, 5408-5417. [CrossRef]

47. Zhang, S.W.; Shi, W.; Cheng, P. The coordination chemistry of N-heterocyclic carboxylic acid: A comparison of the coordination polymers constructed by 4,5-imidazoledicarboxylic acid and 1H-1,2,3-triazole-4,5-dicarboxylic acid. Coord. Chem. Rev. 2017, 352, 108-150. [CrossRef]

48. Gangu, K.K.; Maddila, S.; Jonnalagadda, S.B. A review on synthesis, crystal structure and functionality of naphthalenedicarboxylate ligated metal-organic frameworks. Inorg. Chim. Acta. 2017, 466, 308-323. [CrossRef]

49. Razavi, S.A.A.; Morsali, A. Linker functionalized metal-organic frameworks. Coord. Chem. Rev. 2019, 399, 213023. [CrossRef]

50. Xie, X.X.; Yang, Y.C.; Dou, B.H.; Li, Z.F.; Li, G. Proton conductive carboxylate-based metal-organic frameworks. Coord. Chem. Rev. 2020, 403, 213100. [CrossRef]

(C) 2020 by the authors. Licensee MDPI, Basel, Switzerland. This article is an open access article distributed under the terms and conditions of the Creative Commons Attribution (CC BY) license (http://creativecommons.org/licenses/by/4.0/). 